\title{
Erratum to: Sustainable Population in the Background of Sustainable Development Goals
}

\section{Erratum to:}

\section{Chapter 13 in: B. SyamRoy, India's Journey Towards}

Sustainable Population,

DOI 10.1007/978-3-319-47494-6_13

The book was inadvertently published with identical contents in the lines 6 and 7 at page 224 of Chapter 13. The lines 6 and 7 in that page should read

Goal 6: Combat HIV/AIDS, malaria and other diseases

Goal 7: Ensure Environmental Sustainability

Also at page 226, Goal 7 should read Ensure Environmental Sustainability

The updated original online version for this chapter can be found at 10.1007/978-3-319-47494-6_13

B. SyamRoy $(\bowtie)$

Kolkata, West Bengal, India

e-mail: bpsyamroy@yahoo.co.in 